\title{
Seismic damage zone and width-throw scaling along the strike-slip faults in the Ordovician carbonates in the Tarim Basin
}

\author{
De-Bo Ma ${ }^{1,2} \cdot$ Guang-Hui Wu ${ }^{1} \cdot$ Nicola Scarselli ${ }^{3}$ Xin-Sheng Luo ${ }^{4} \cdot$ Jian-Fa Han ${ }^{4} \cdot$ Zhi-Yong Chen $^{2}$
}

Received: 11 April 2018 / Published online: 10 August 2019

(c) The Author(s) 2019

\begin{abstract}
Understanding the scaling relation of damage zone width with displacement of faults is important for predicting subsurface faulting mechanisms and fluid flow processes. The understanding of this scaling relationship is influenced by the accuracy of the methods and types of data utilized to investigate faults. In this study, seismic reflection data are used to investigate the throw and damage zone width of five strike-slip faults affecting Ordovician carbonates of the Tarim intracraton basin, NW China. The results indicate that fault slips with a throw less than $200 \mathrm{~m}$ had formed wide damage zones up to $3000 \mathrm{~m}$ in width. Also, damage zone width is found to have both a positive correlation and a power-law relation with throw of two orders of magnitude, with a ratio of these values varying in a range of $2-15$. The relationship between throw and damage zone width is not a simple power-law and changes its slope from small to larger size faults. The results indicate that throw scales well with damage zone width for the studied faults, and hence these can be used to predict fault geometries in the Tarim Basin. The study of the wide carbonate damage zones presented here provides new insights into scaling of large-size faults, which involve multiple faulting stages.
\end{abstract}

Keywords Fault damage zone $\cdot$ Carbonate $\cdot$ Throw $\cdot$ Scaling $\cdot$ Evolution $\cdot$ Tarim Basin

\section{Introduction}

Faults usually exhibit narrow, highly deformed cores and wider damage zones (e.g., Kim et al. 2004; Agosta et al. 2012). Damage zone widths can vary from tens of meters to kilometers, significantly influencing the mechanical behavior and fluid flow properties of faulted rocks (Caine et al. 1996; Aydin 2000; Peacock 2002; Kim et al. 2004; Torabi and Berg 2011; Pei et al. 2015; Choi et al. 2016). Therefore,

Edited by Jie Hao

Guang-Hui Wu

wugh@swpu.edu.cn

1 School of Geoscience and Technology, Southwest Petroleum University, Chengdu 610500, Sichuan, China

2 PetroChina Research Institute of Petroleum Exploration and Development, Beijing 100083, China

3 Fault Dynamics Research Group, Department of Earth Sciences, Royal Holloway University of London, Egham TW20 0EX, UK

4 PetroChina Tarim Oilfield Company, Korla 841000, Xinjiang, China scaling of damage zone width with fault displacement (or length) is crucial for understanding and predicting mechanical, hydraulic and seismological properties of faults. In the last few decades, the study of well-exposed fault outcrops found a disparity of relationships between damage zone width and displacement: linear (Shipton and Cowie 2001; Choi et al. 2016), logarithmic (Fossen and Hesthammer 2000) and power-law (Faulkner et al. 2011; Torabi and Berg 2011). Also, scaling of damage zone width and displacement has been found to be generally large, scattering over two to four orders of magnitude (e.g., Torabi and Berg 2011). These differences could be related to a variety of factors that can influence the width of damage zones such as, the nature of the protolith, depth of faulting, effect of diagenesis and deformation mechanisms (e.g., Faulkner et al. 2011; Laubach et al. 2014; Choi et al. 2016). Recent advances in acquisition and processing of seismic reflection data and the availability of extensive, high quality 3D seismic surveys have allowed the study of the geometry of large faults in the subsurface, which is usually not possible from the investigation of outcrops only (e.g., Liu et al. 2011; Hale 2013; Wu et al. 2016; Iacopini et al. 2016; Botter et al. 2016; Torabi et al. 2017). Nonetheless, research on fault damage zones in 
carbonate rocks based on seismic reflection data is scarce (Iacopini et al. 2016; Wu et al. 2019).

In recent years, significant hydrocarbon exploration effort in China has been focused toward carbonate reservoirs, particularly those found in the Tarim Basin (e.g., Du 2010). The basin has attracted much attention for its significance as a new exploration frontier and for the study of Early Paleozoic carbonate reservoirs that are rare in the world (e.g., Pang et al. 2010; Li et al. 2010; Zhu et al. 2014). In the basin, considerable hydrocarbon accumulations are structurally trapped along prominent fault zones (Du 2010; Wu et al. 2012, 2016; Lan et al. 2015). Despite the recognition that these fault zones are important pathways for hydrocarbon migration (e.g., Lü et al. 2008; Wu et al. 2012, 2016; Lan et al. 2015), exploration and production targeting these structures have been proved to be challenging (Pang et al. 2010; Du 2010).

In this research, core data, high-resolution seismic data together with the implementation of seismic attributes were used to characterize a number of fault damage zones associated with strike-slip faults in the Tarim Basin. Vertical displacement (throw) in Ordovician carbonate along five fault zones was measured. Furthermore, the scaling relationship of carbonate fault damage zone widths with throw was investigated. Finally, a model for the growth of damage zones in carbonate rocks is proposed.

\section{Geological setting}

With an area of $\sim 560,000 \mathrm{~km}^{2}$, the Tarim Basin is the largest petroliferous basin in northwest China (Fig. 1). The basin is floored by Archean-Early Neoproterozoic crystalline basement that is covered by a thick, Late NeoproterozoicQuaternary sediments affected by polyphase tectonism: (1) supercontinent assembly and breakup in Late Neoproterozoic, (2) opening and closure of the Tethys and the PaleoAsian Ocean during the Paleozoic and Mesozoic and (3) the Indo-Asian collision in the Cenozoic (Jia 1997; Li et al. 2010; Wu et al. 2016 and references therein). This complex history is recorded in the basin by the occurrence of a series of subbasins divided by structural highs (see 'uplifts' and 'depressions' in Fig. 1a).

The largest Ordovician condensate field in China was discovered in recent years in the northern slope of the Central Uplift (Du 2010; Zhu et al. 2014). This region covers an area of $22,000 \mathrm{~km}^{2}$ in the central part of the Tarim Basin (Fig. 1; Wu et al. 2012, 2016) and contains Cambrian-Late

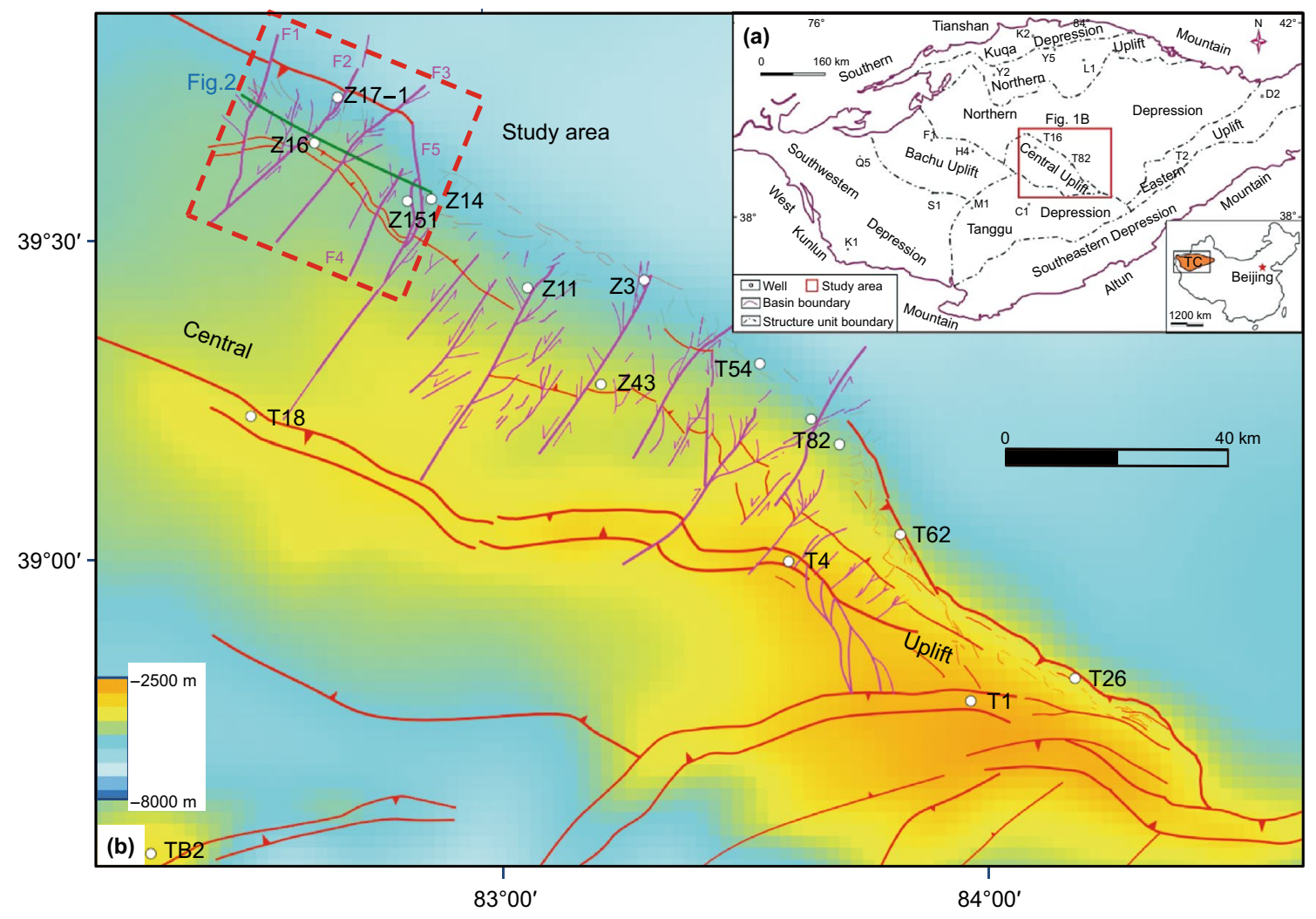

Fig. 1 a Tectonic map of the Tarim Basin (after Wu et al. 2016); b map of the fault system affecting the Lower Paleozoic in the Central Uplift of the Tarim Basin (after Wu et al. 2016) 
Ordovician carbonates with thicknesses in excess of $2000 \mathrm{~m}$. Recently acquired 3D seismic data have revealed that this stratigraphic section is affected by numerous strike-slip faults (Figs. 1, 2, 3; Wu et al. 2012, 2016; Li et al. 2013; Lan et al. 2015). In the survey area, there are five major NE-trending strike-slip faults with lengths more than $40 \mathrm{~km}$
(Figs. 1, 2, 3). Seismic profiles show that faults have nearly vertical slip surfaces with a narrow and steep fault zone (Fig. 2). Most faults exhibit small splays (Fig. 3) which may form positive, negative flower and half flower structures (Fig. 2). The faults often affect the carbonate rocks of Cambrian-Upper Ordovician age, and some extend upward

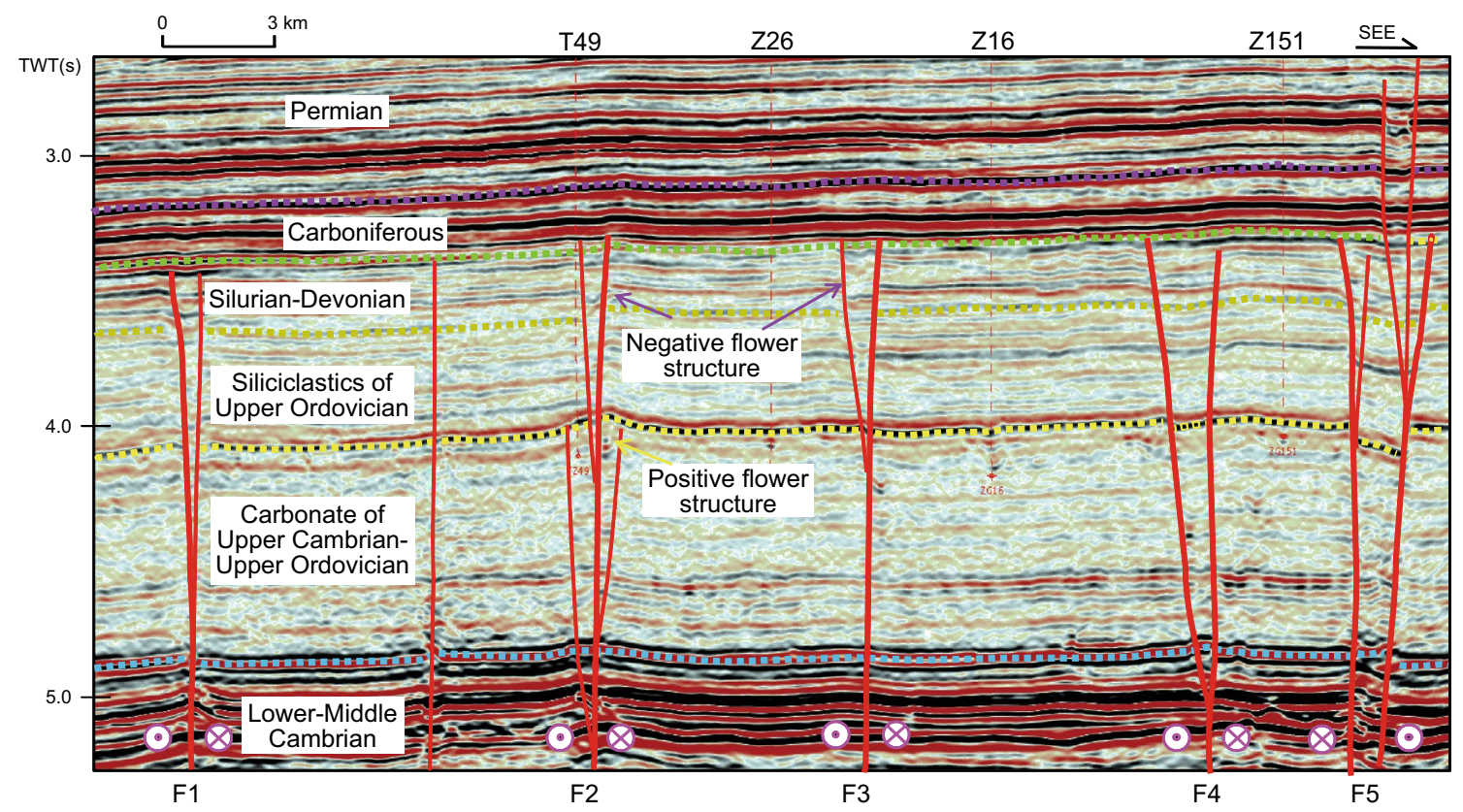

Fig. 2 Seismic profile across the study area showing fault and stratigraphy interpretations. The vertical dashed lines show the well locations. Key faults are marked and named at the bottom of the profile. See Fig. $1 \mathrm{~b}$ for location of the seismic line
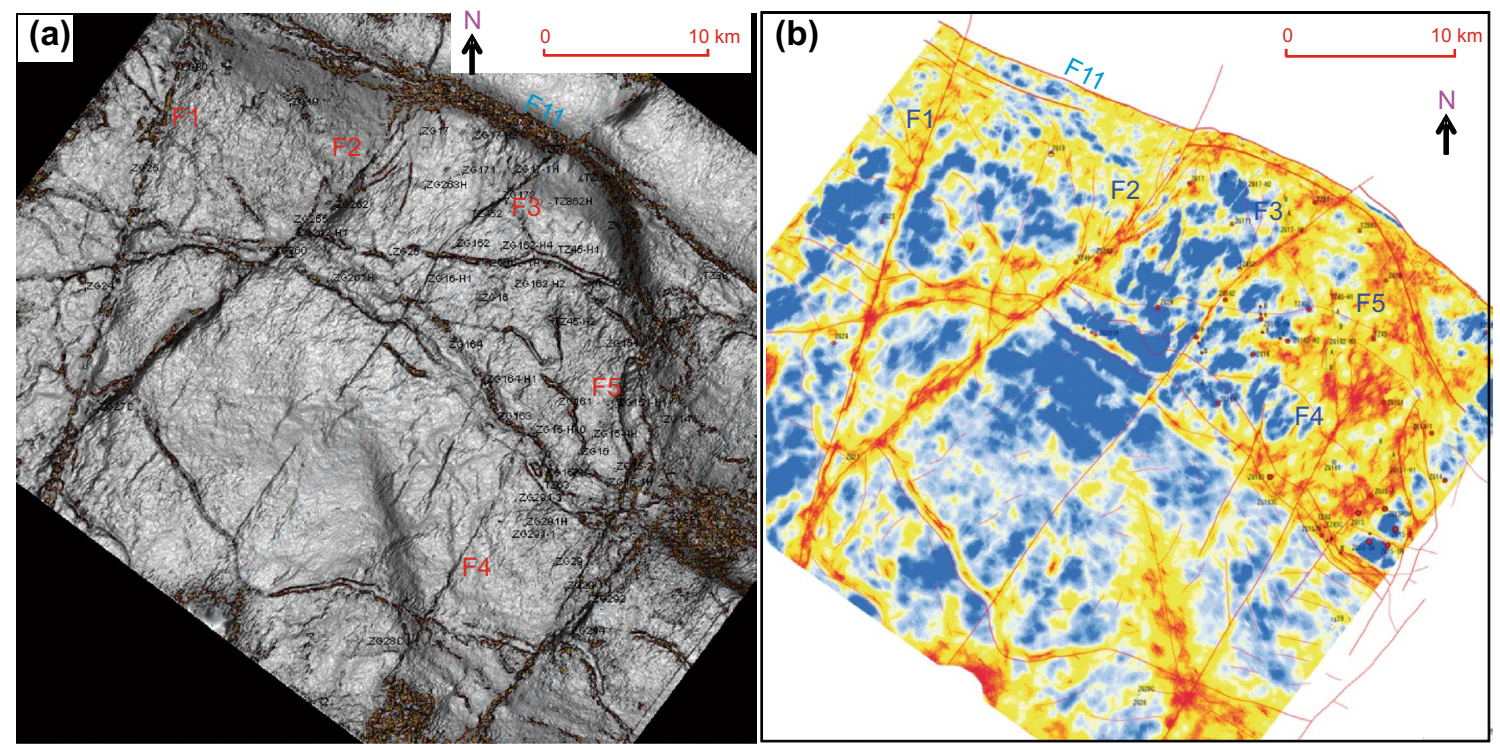

Fig. 3 a Seismic coherence attribute and b amplitude attribute maps of the top of the Upper Ordovician carbonates (after Neng et al. 2018). In the coherence attribute shown in a, the dark black stripes indicate the NE-SW trending strike-slip fault zones and associated splay segments. In the amplitude attribute in $\mathbf{b}$, the orange areas are high amplitude anomalies interpreted to highlight the envelopes of damage zones along the strike of the fault zones 
into the Silurian-Devonian, and into the Permian (Fig. 2; Wu et al. 2012, 2016; Li et al. 2013; Lan et al. 2015; Neng et al. 2018).

A large platform margin to reef-shoal complex developed in the Late Ordovician along the northern part of the study area (Du 2010; Gao and Fan 2015). These carbonates form reservoirs that differ significantly from the high matrix porosity carbonates described in other parts of the world (Du 2010). Except for a few fracture-caves with high porosity and permeability, the reservoirs are tight with low matrix porosity $(<5 \%)$ and low permeability $(<0.5 \mathrm{mD})$ and marked lateral heterogeneity (Du 2010; Wu et al. 2016). A network of dense fractures was found in the fault damage zones affecting the Ordovician carbonate (Ding et al. 2012; Wu et al. 2016). Except for numerous horizontal stylolites, the fractures are mainly high angle and with narrow aperture (Wu et al. 2016). Within the fault damage zones, there are generally one or two sets of opening-mode fractures. Breccias and cataclastic rocks developed in parts of the fracture networks. The majority ( $>70 \%)$ of the fractures are filled with calcite cements, as well as bitumen and argillaceous or arenaceous limestones. Some unfilled or residual dissolution porosity is still preserved along the fractures (Du 2010). Previous studies have found that there have been multiple stages of fracturing and diagenesis along these fault zones (Du 2010; Wu et al. 2016).

\section{Data and methods}

More than twenty wells and $\sim 1500 \mathrm{~km}^{2}$ of high-resolution, $3 \mathrm{D}$ seismic reflection data were used to investigate fault damage zones in this study area (Figs. 1b, 2). This dataset allowed detailed fault interpretation (Wu et al. 2012, 2016; Li et al. 2013; Lan et al. 2015) and reservoir description of the carbonates (Du 2010). Seismic well ties were used to calibrate the stratigraphy from the well data to the seismic units (Fig. 2). The occurrence of flower structures, abrupt changes of the upthrown side and dips allowed identification of strike-slip faults (Wu et al. 2012, 2016; Li et al. 2013; Lan et al. 2015). The identification was based on the integration of vertical seismic profiles with coherence and amplitude coherence seismic attributes computed along time slices (Fig. 3). Using this technique, five large strike-slip fault zones were mapped in the study area (Fig. 1b, 3) (Wu et al. 2016; Neng et al. 2018).

Time structure maps were implemented to measure fault throw and horizontal separation in order to pursue geometric and kinematic analysis of faults. Since the breakup point between hanging-wall and footwall was hard to identify in wide deformation zones and also fault drags could lead to an underestimation of displacement (Fig. 4; Kim et al. 2004), vertical height differences measured in seismic sections
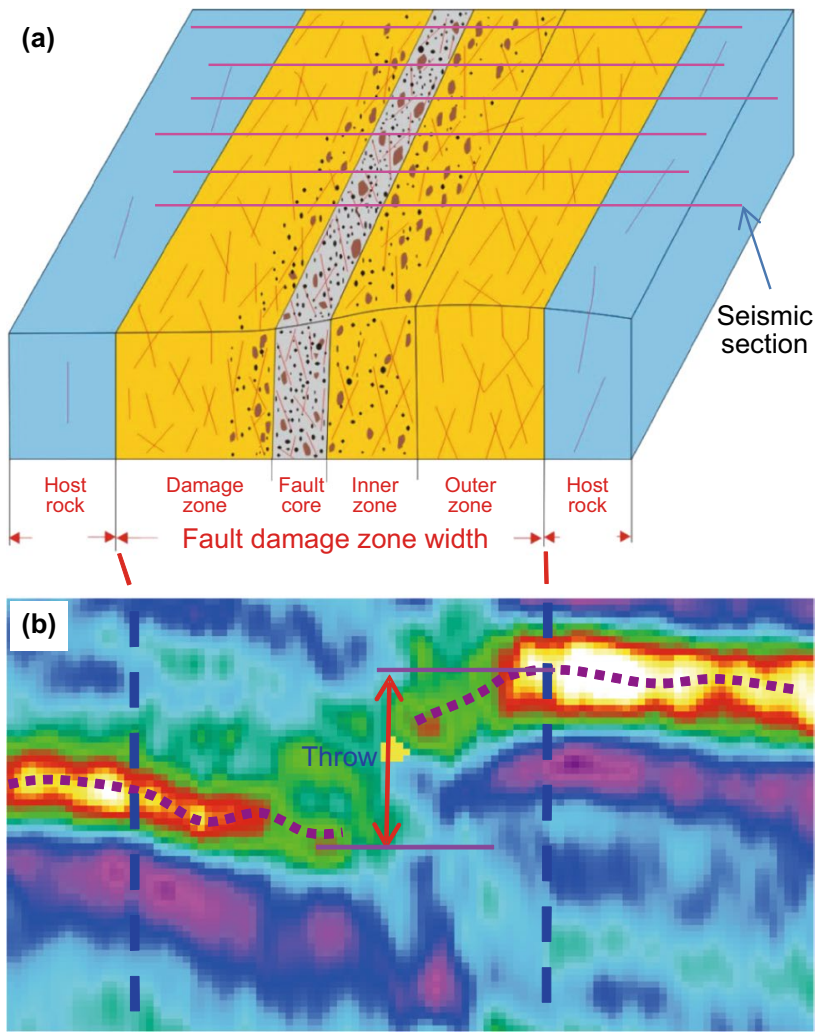

Fig. 4 a Schematic diagram showing a geological model of damage zone (after Faulkner et al. 2010; Choi et al. 2016). Red lines indicate fractures and dots indicate fault breccias. b Key seismic profile showing the typical chaotic to discontinuous seismic reflection characteristic of fault damage zones. The dash lines indicate the boundaries of damage zones as observed by abrupt changes in the seismic attributes as well as highlighted by discontinuous reflections in the profiles (see text for further details)

were used to characterize throw along faults (Wu et al. 2016). Thus, we used throw ( $\Delta H$; vertical height difference) between the maximum and minimum depth of the fault as a proxy for the vertical displacement (Fig. 4). It was estimated that for the faults in the study area, throw may be $10 \%-40 \%$ larger than vertical displacement. Considering that vertical seismic resolution is in the order of $10 \mathrm{~m}$ (Du 2010; Wu et al. 2016), fault tips are undetectable in seismic (Pickering et al. 1997). The offset of the structures, stratigraphy or microfacies, and seismic attributes in time slices were integrated to identify the horizontal separation of the two fault planes. The horizontal separation value corresponding to throw was interpolated by several horizontal separation values of a fault zone. The total displacement along a fault zone can be inferred by the vertical and horizontal displacement. Some errors in vertical and horizontal components needed correction, but they were relatively small and did not affect the displacement.

Although the exact locations of the boundaries of a fault damage zone were not possible to identify because 
of seismic resolution limitation, the fault envelope, which includes fault core and damage zone (Fig. 4a), has low velocity characteristics that reflect the attenuation structure of faults (Koch 1992; Wu et al. 2016; Botter et al. 2016; Wan et al. 2016; Torabi et al. 2017). For this reason, fault damage zones are seismically characterized by discontinuous and low-amplitude reflections (Fig. 4b). In places, damage zones are seismically continuous, but can show weak amplitudes and low frequencies. In seismic profiles, the abrupt changes in seismic facies across a fault damage zone can possibly correspond to the fault envelope (Fig. 4b). This facies progressively changes to high-amplitude continuous reflections identifying the undeformed host rocks. It may be difficult to identify this boundary in low-resolution seismic data. Thus, the distinct disrupted seismic facies seen in seismic sections probably correspond to a highly deformed inner damage zone and fault core (Fig. 4b; e.g., Botter et al. 2016; Wu et al. 2019). This implies that estimation of the width of damage zones from seismic section is likely smaller than the actual width. In addition, the abrupt and gradual changes in the boundary between fault envelope and the host rocks can be highlighted by seismic attributes (Fig. 3; e.g., Iacopini et al. 2016; Botter et al. 2016; Wan et al. 2016). Since seismic coherence and amplitude data are sensitive to fault damage zones (Wan et al. 2016; Wu et al. 2019), these attributes were integrated in this study to map fault damage zones (Fig. 3). Furthermore, the fracture density of host rocks and damage zones were evaluated from rock core samples and formation micro-imaging (FMI) logging data (Wu et al. 2016). By comparing these, portions of wells located in a damage zone were identified. Since the damage zone boundaries are gradual (Mitchell and Faulkner 2009), a combination of both interval and cumulative frequency methods was useful in defining damage zones and estimating their width (Choi et al. 2016; Wu et al. 2019).

The workflow followed in this research was: (1) to map the transition boundary between discontinuous, weak reflection in the fault zone and continuous reflection in the host rocks in seismic profiles; (2) to calibrate seismic mapping using well data to correct damage zone boundaries from cores and FMI logs; and finally (3) to identify the fault envelope width (including the fault core and damage zone) by using both vertical seismic sections and seismic attributes analysis. It should be noted that the fault damage zone width analysis was subject to some uncertainties (around tens of meters) - this was considered to be in an acceptable uncertainty range for our statistical analysis.

Following the abovementioned calibration, the damage zone width $\left(W_{\mathrm{d}}\right)$ and throw $(\Delta H)$ in seismic profiles along the fault zones were measured. The sampling density was $\sim 500 \mathrm{~m}$ for the scaling purpose in this research. The measurements were not performed close to the fault tips because of the seismic resolution issues. In addition, measuring small throw and damage zone width in minor faults was avoided because of possible ambiguity of the data in defining both throw and damage zone width.

\section{Scaling of damage zone}

\subsection{Univariate distribution of fault throw and damage zone width}

Damage zone width and throw were measured along five major strike-slip faults at the top of the Ordovician carbonate (Fig. 5). The damage zone width and throw largely vary along fault strike, but displayed a positive relationship of throw with damage zone width (Fig. 5). When looked individually, most throw values were less than $200 \mathrm{~m}$ with a peak of 40-60 m. Damage zone width showed great variability with highest value in excess of $3000 \mathrm{~m}$, but most were in the range of $100-800 \mathrm{~m}$. Due to seismic resolution issues, fault tips and small faults were neglected and hence underestimated in this analysis (Fig. 5).

Well data have been used as an identification criterion for damage zone width in the seismic profile, and the identified damage zone width was also calibrated by newly drilled wells. The distribution of cumulative fracture frequency
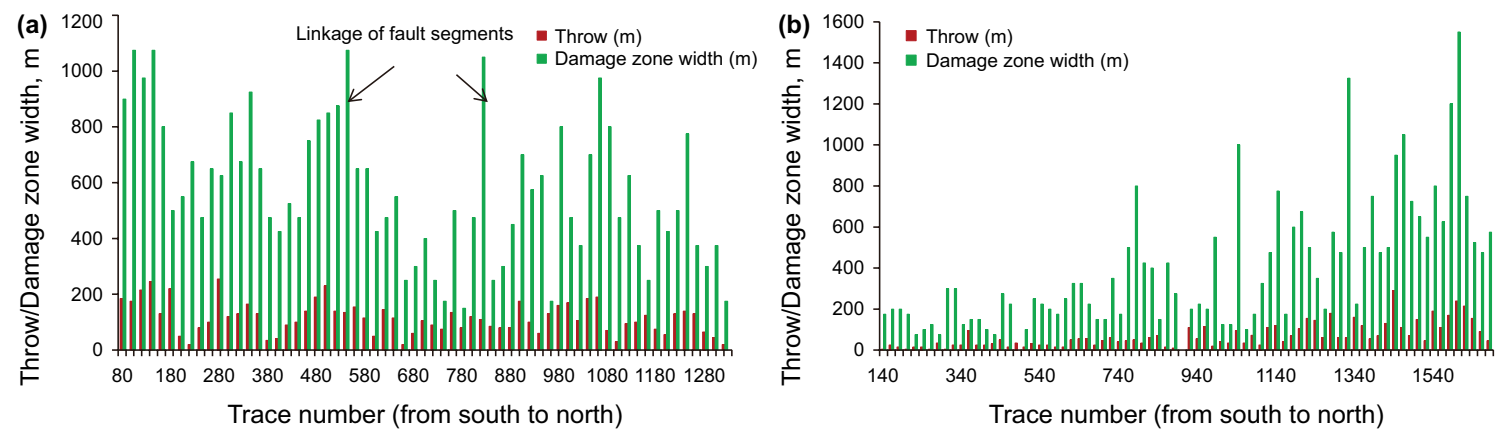

Fig. 5 Width of damage zones and associated throw of the top of the Ordovician carbonates along the strike of $\mathbf{a}$ fault F2, and $\mathbf{b}$ fault F3 
from the analysis of core and FMI log data can be used to define a damage zone width (Choi et al. 2016; Wu et al. 2019). This study shows a reduction in fracture frequency with distance, likely depending on the size and displacement of the associated fault. In addition, more than $90 \%$ of the wells are deployed in the fault damage zones for high and stable production (Wu et al. 2016). Production data indicate high production wells are within a range of $800 \mathrm{~m}$ from the fault core (Wu et al. 2019). This is in agreement with high fracture frequency in the damage zones that may have enhanced poro-permeability of the carbonate reservoirs ( $\mathrm{Wu}$ et al. 2016). These data together with seismic attributes were used to constrain and test the accuracy of the fault damage zone width measured in seismic profiles. By comparison, the damage zone width measured in seismic profile is consistent with the measurement from seismic attributes, fracture and production distribution (Wu et al. 2019), which supports the validity of the scaling analysis of fault damage zone with width presented here.

\subsection{Fault damage zone width scaling with throw}

We measured both horizontal and vertical separation for the strike-slip faults at the top of the Ordovician carbonate rocks. The total displacement was calculated from these values and was correlated with the measured fault throw (Fig. 6). There is a large scatter in the data with relatively low correlation coefficient, particularly for smaller faults (e.g., F4 in Fig. 6). This may be due to the fact that throw varies quickly along fault strike, which is not consistent with the variation of the interpolated horizontal separation. For fault F5, there was much larger horizontal separation than the throw values, indicating that the total displacement was controlled by horizontal separation. Both fault throw and total displacement data showed positive correlation with

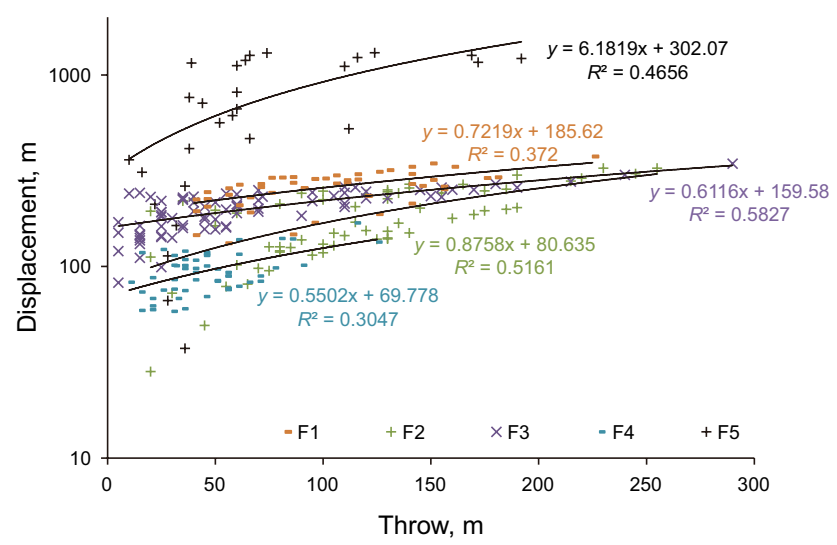

Fig. 6 Total displacement versus the throw of the strike-slip faults in the study area. Displacement and throw were calculated for the top of Ordovician carbonates damage zone width (Fig. 7), while the correlation coefficient for throw-damage zone width was larger than that of the total displacement versus the damage zone width. This suggests that the throw data are more reliable for scaling with damage zone width rather than using the total displacement.

The data in this study come from similar lithology, depth and deformation histories. All are left lateral faults, except for the dextral fault F5. Apart from F4 which is a small-scale fault influenced by intersecting a larger structure, all faults showed a positive correlation between the damage zone and the throw values (Fig. 7). The fault damage zone width varied laterally with throw along the fault strike, although there was a general scatter in the data. The data compiled showed that the damage zone width $\left(W_{\mathrm{d}}\right)$ scales with throw $(\Delta H)$ in a linear relation. When compiling the entire fault throw data versus width of damage zone (Fig. 8), in most cases, the damage zone $\left(W_{\mathrm{d}}\right)$ was considerably larger than its throw measurements $(\Delta H)$. The data compiled also showed that the damage zone width $\left(W_{\mathrm{d}}\right)$ scaled with throw $(\Delta H)$ in a positive relation with a variation of two orders of magnitude, although there is a general scatter in the data (Fig. 8). It noted that most of the $W_{\mathrm{d}} / \Delta H$ values are in the range of 2-15 with few high anomaly values. Compared with published data (Torabi and Berg 2011 and the references therein), the throw data cover two orders of magnitude on the plot and consistently fits in a power-law trend with damage zone width.

\section{Discussion}

\subsection{Scaling of damage zone}

In the Ordovician carbonate rocks of the study area, all fault zones have wider damage zones with respect to their displacement compared to previous studies on fault damage zones (e.g., Torabi and Berg 2011; Bastesen et al. 2013; Choi et al. 2016). Oil and gas exploitation in the Central Uplift has confirmed that there are wide damage zones in the faulted Ordovician carbonate which can be up to $3 \mathrm{~km}$ based on the fracture densities from well data (Wu et al. 2016; Neng et al. 2018). In addition, analysis of seismic attributes also supports wider damage zones in these carbonate reservoirs (Fig. 3; Wan et al. 2016). The damage zone width has a positive correlation with the throw (Figs. 6, 7). However, scattering of data indicated that there may be multiple stages of damage zone growth, inconsistent with a simple linear or power-law correlation (e.g., Torabi and Berg 2011). Seismic attributes are generally efficient in highlighting fault zones (Iacopini et al. 2016; Botter et al. 2016; Wan et al. 2016). In this study, seismic coherence and amplitude attributes were crucial to constrain fault damage zones in the Ordovician carbonates of the Tarim Basin (Fig. 3; Wu et al. 

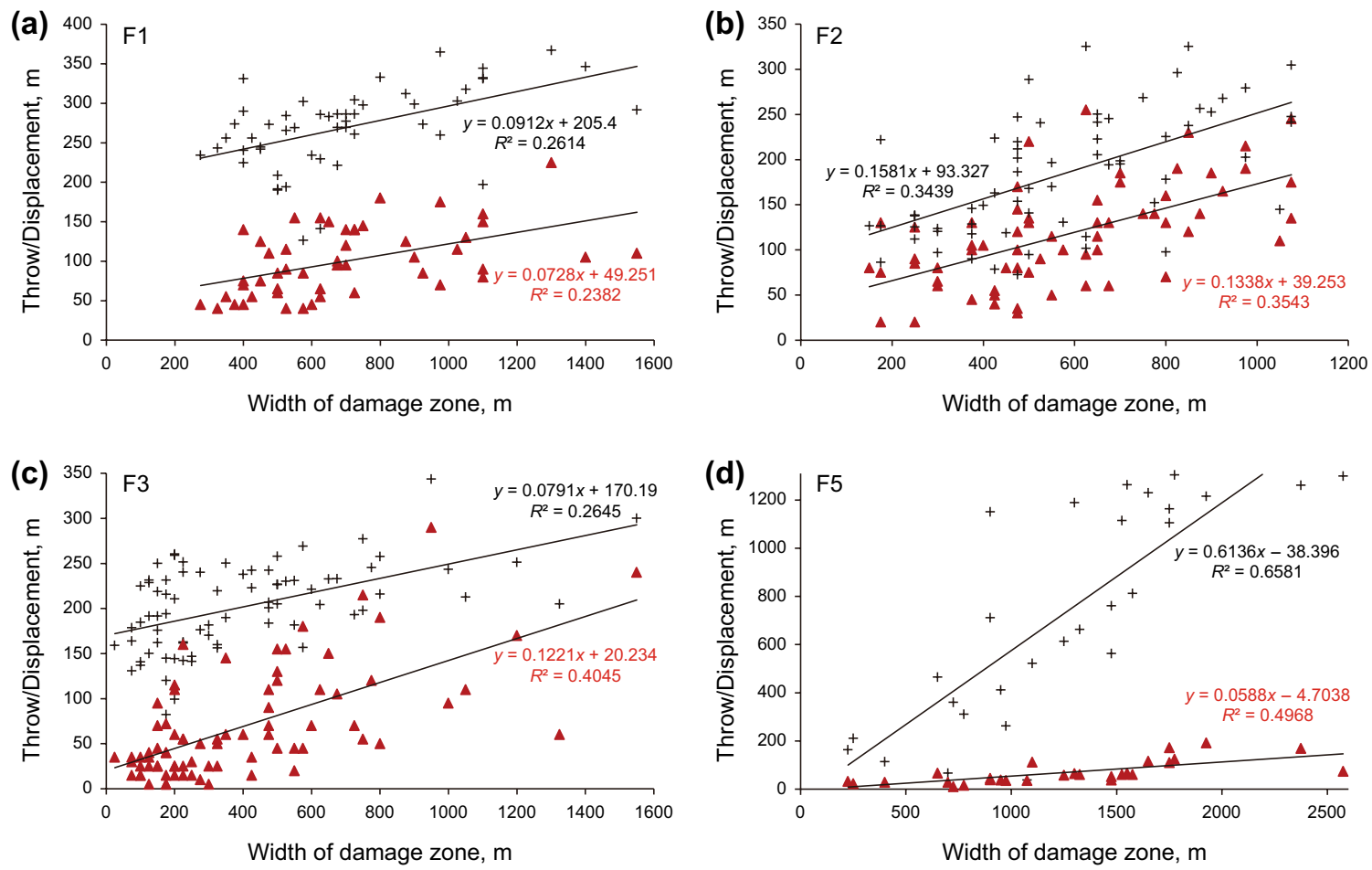

Fig. 7 Plots of width of damage zone versus the throw (red triangle) and displacement (black cross) for the top of the Ordovician carbonates

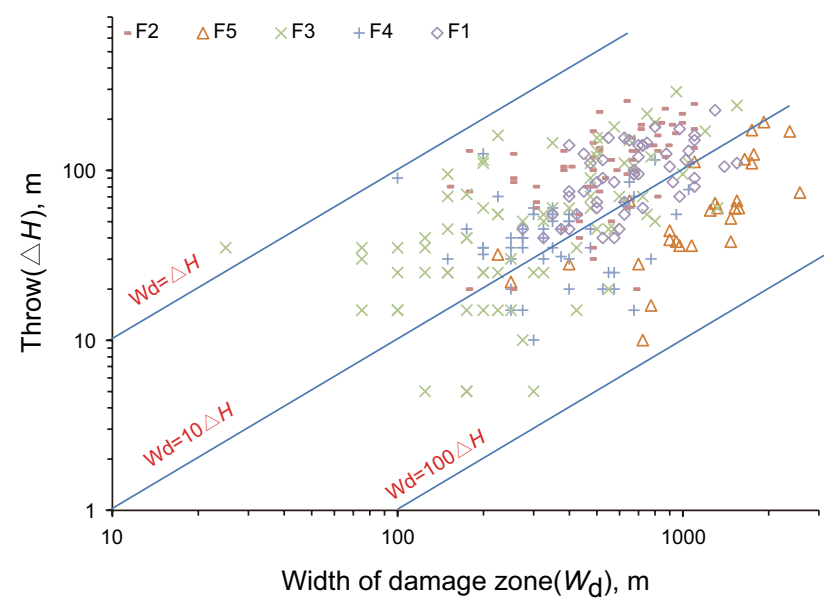

Fig. 8 Plots of width of damage zone $\left(W_{\mathrm{d}}\right)$ versus the throw $(\Delta H)$ of the Ordovician carbonate along the strike-slip faults in the study area

2016; Neng et al. 2018). Well data, together with seismic profiles and attributes, were useful in assessing the width of the fault envelope and for resolving a potential quantitative scaling with displacement (throw). This scaling, however, was affected by uncertainty related to the precise definition of fault damage zone width that can vary by the order of tens of meters. Also, both seismic facies definition and seismic attributes analysis were affected by sampling bias, and identification of fault damage zone boundaries can be also affected by seismic data quality and resolution. Precise identification of damage zone width from seismic integration of more data and further detailed study aimed to improve the sensitivity of seismic profiles and seismic attribute analysis would be required. This indicates that a simplistic interpretation that only relies on seismic data can easily hinder a solid evaluation of fault damage zones (e.g., Iacopini et al. 2016).

This study showed a positive relationship between damage zone width and throw (Figs. 7, 8). However, plotting the current data with previous published data in a log-log plot reveals that the dataset has a distinct positive linear correlation, which fits well with the power-law relation described by Kolyukhin and Torabi (2012). The damage zone width and throw ratio $\left(W_{\mathrm{d}} / \Delta H\right)$ is mainly in the range of 2-30, and nearly proportionally distributed where the damage zone is less than $1000 \mathrm{~m}$ in width (Fig. 8). In the average displacement/throw versus width plots of the five fault zones (Fig. 9a), these show a clear correlation. These averaged values may have smoothed out anomalies related to the influence of secondary faults and to seismic data quality. When outlying values were filtered out, the fault throw-width plots also showed an explicit positive relationship with scattering of samples less than 2 orders of magnitude (Fig. 9b). These indicated that the proxy of throw instead of displacement is effective for predicting damage zone width in carbonate strike-slip fault zones in the subsurface. 

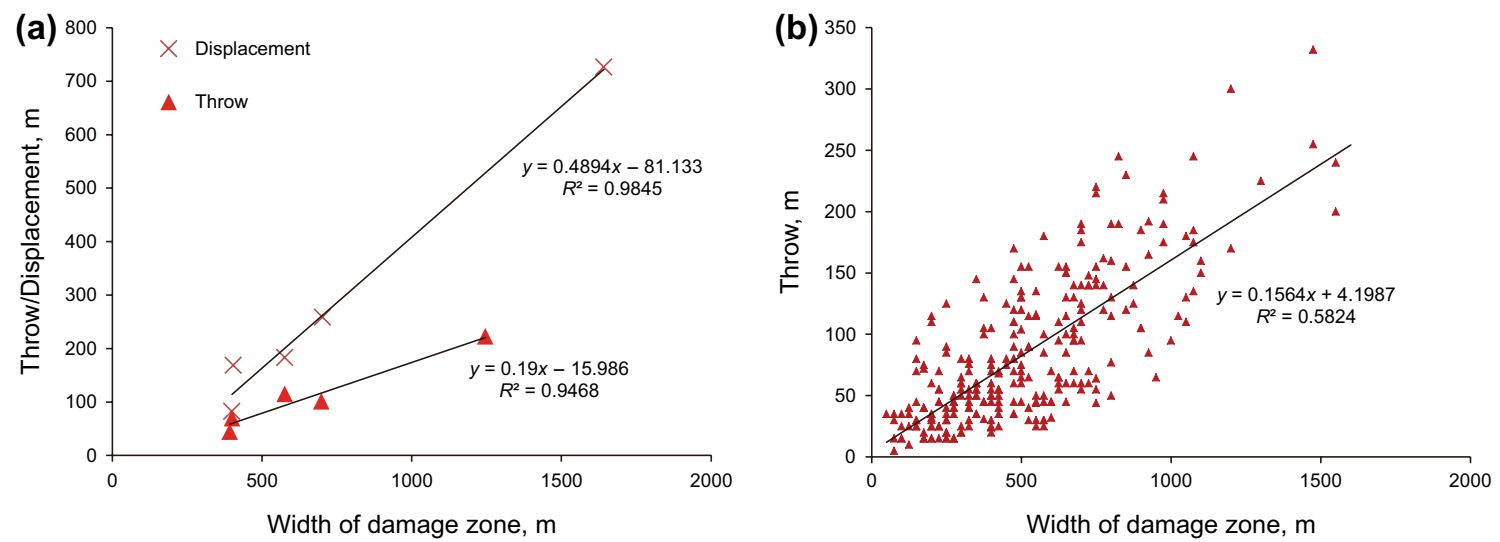

Fig. 9 a Plot of average damage zone width versus average throw/displacement along a fault zone of the strike-slip faults; $\mathbf{b}$ plot of width of damage zone versus the throw for the top of the Ordovician carbonate (the data are the same of those displayed in Fig. 8 with anomalously high values being excluded)

Torabi and Berg (2011) envisaged that due to gaps in datasets, medium-to-large-size faults exhibit an increased slope in the power-law relation between fault displacement and damage zone width. Our study supports the power-law relationship for medium to large size faults in carbonate rocks. However, the growth of medium-size damage zone width does not decrease with the increase in displacement except for F5 (Figs. 7, 8, 9), and even occurred as an increase in the damage zone width of some faults. The results of this study also differ from the damage zone width growth model of Faulkner et al. (2011), which has a distinct transition zone of slower damage zone growth when the displacement is in the range of 10-100 m. Although there are differences in the data, our work showed another damage zone growth trend in which growth with displacement does not slow down from small-size to medium-size faults. Following this, this work supports that there is a similar evolutionary process of damage zone width from small to medium scale faults. The growth of damage zone width keeps pace with displacement in medium size as a whole, but each fault in the study area may have a different process trajectory.

Due to the different scatter distribution in each fault (Fig. 7), the relationship of damage zone width and throw could not be simplified as linear or logarithmic correlation. Some of them exhibit both high and low growth with throw, or both linear and logarithmic trends. Therefore, the scaling of fault damage zone width with displacement shows generally a positive correlation between the two attributes in the same geological setting. The relation could vary for specific faults and its variation depends on the variation along the fault strike. Whatever the processes of damage zone formation, the scaling relationships presented here are helpful for predicting geometries of fault zones in the Tarim Basin and possibly elsewhere.

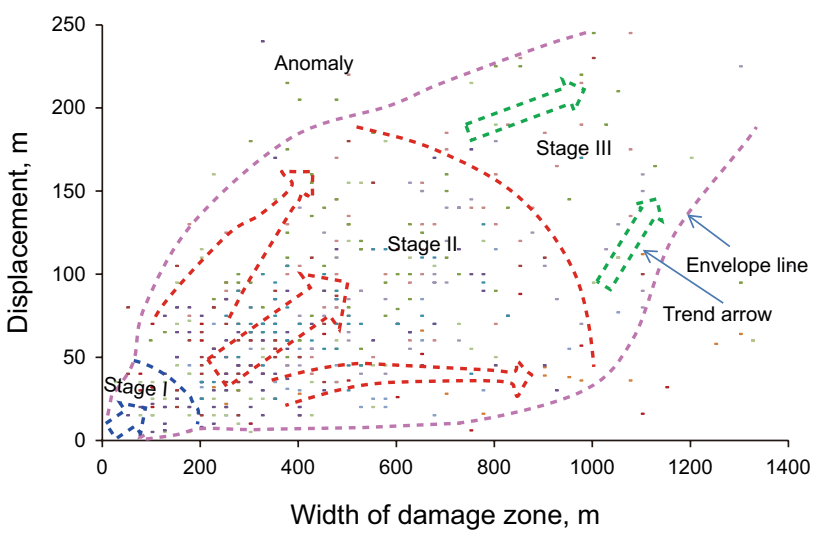

Fig. 10 Conceptual diagrams for fault damage zone width growth with the displacement in carbonate strike-slip faults of the Tarim Basin. The background data are throw versus damage zone width of the Ordovician, the same as those shown in Fig. 8

\subsection{Damage zone evolution}

Previous studies show that the growth of fault damage zones is related to the protolith, depth, deformation mechanism, diagenesis and their interactions (Kim et al. 2004; Mitchell and Faulkner 2009; Torabi and Berg 2011; Agosta et al. 2012; Gudmundsson et al. 2013). In this study, the top Ordovician limestones are buried at depths of 5900-6200 m and consist of an uniform slope platform facies of wackstone and packstone (Du 2010; Gao and Fan 2015). As a consequence, the lithology and burial effects would be negligible for the Ordovician carbonates. Irrespective of the complexities of fault damage zones, the data presented in this study (Figs. 8, 9) allow proposing a three-stage evolution for damage zones associated with strike-slip fault in the carbonates of the Tarim Basin (Fig. 10). 
At fault initiation (Stage I in Fig. 10), there is large scattering of values for damage zone growth with an increase in throw, regardless of the sparse data. The divergence of data is within $\sim 200 \mathrm{~m}$ for width and $\sim 50 \mathrm{~m}$ of throw. During this stage, the $W_{\mathrm{d}} / \Delta H$ ratios vary in a large range, suggesting a lack of relationships between growth of damage zone width and throw. This could indicate multiple models of fault growth and linkage as well as influence of local stress perturbations (Knott 1994; Kim et al. 2004; de Joussineau and Aydin 2007; Gudmundsson et al. 2013). Furthermore, variability in fault architecture and diagenesis might indicate that mechanical properties of the damage zone have caused considerable anisotropy along the fault zone (e.g., Laubach et al. 2014; Haines et al. 2016; Wu et al. 2019), which may also account for the lack of a simple linear or power-law distribution of the damage zone width and throw in the faults. Constrained by limited data and issues related to seismic resolution, fault initiation mechanisms need further studies to be better elucidated.

In spite of the lack of a distinct boundary for a second stage (Stage II in Fig. 10), the data show obvious divergent growth trends. Most damage zones keep the similar trend as seen in Stage I with larger growth of width with respect to throw. This may indicate continuous cumulative processes of off-fault damage after fault formation. In this stage, there is no variation in the relationship between attribute populations derived from small- and medium-size faults, whereas some of the damage zone widths, particularly in F3 and F2, show slower growth to gradual increase as throw increases (Fig. 7). The low $W_{\mathrm{d}} / \Delta H$ ratio of 5 also indicates a decreased damage zone growth. On the other hand, other damage zones in the second stage, mainly F5, have higher width increase (Figs. 7,8 ). The damage zone width enlarged to about $1600 \mathrm{~m}$, but the throw was still $\sim 60 \mathrm{~m}$. As a consequence, in this stage, there are examples of fault damage zone width that show linear and power-law correlation with throw.

In the third stage (Stage III in Fig. 10), the damage zone width still increased with throw, but the values show less scattering (Figs. 8, 10). The high growth of the damage zone width in the second stage slows down quickly with the increase in throw. The break in the scaling of damage zone width with displacement can be the result of a change of mechanical properties, such as softening, or stress localization in fault cores, or both (e.g., Shipton and Cowie 2003; Torabi and Berg 2011; Gudmundsson et al. 2013). The slow growth of damage zone width with throw in previous stages, however, has a significant transition to increase. The mechanical properties hardening by extensive cementation in the fault zones probably account for the exceptionally rapid growth of damage zone width with throw. Of course, most of the damage zone width increased more slowly in the late stage to show the gradual growth of damage zone width with displacement.
Therefore, a convergent trend of damage zone growth with displacement is expected in the end to show better correlation (Fig. 10).

\section{Conclusions}

Although prediction of subsurface fault damage zones is challenging, seismic data provide a powerful tool for studying the geometry and mechanism of damage zone formation. Based on the data and results from fault damage zones in carbonate rocks of the Tarim Basin, we can propose the following main conclusions:

1. Calibration of well data and seismic attributes suggests that throw is an effective proxy for vertical displacement to correlate with damage zone width.

2. Throw-damage zone width shows a clear positive correlation, with damage zone width-to-throw ratio mainly in the range of $2-15$.

3. The relationship between fault damage zone width and throw is not a simple linear or power-law relation. This study provided data for medium to large scale damage zone width, which was not addressed in the previous literature.

4. A three-stage evolution process of damage zone growth in carbonates is proposed: (1) an early stage with divergent damage zone width growth with increase in displacement; (2) this is followed by divergent trends with high to slow rates of enlargement of damage zone width with throw; and (3) a final stage of convergent growth of damage zone width growth with displacement.

Acknowledgements Tarim Oil Company data access and research support are gratefully acknowledged. The authors are grateful to Anita Torabi (Uni Research CIPR, Bergen, Norway) for her constructive comments that substantially improved the manuscript. The authors thank the reviewers and editors for their detailed comments. We thank Xin Liu, Taiping Hu and Fei Zhao for their help. This study has been partly supported by National Natural Science Foundation of China (Grant No. 41472103) and Technology Major Project (2016ZX05004001).

Open Access This article is distributed under the terms of the Creative Commons Attribution 4.0 International License (http://creativeco mmons.org/licenses/by/4.0/), which permits unrestricted use, distribution, and reproduction in any medium, provided you give appropriate credit to the original author(s) and the source, provide a link to the Creative Commons license, and indicate if changes were made.

\section{References}

Agosta F, Ruano P, Rustichelli A, et al. Inner structure and deformation mechanisms of normal faults in conglomerates and 
carbonate grainstones (Granada Basin, Betic Cordillera, Spain): inferences on fault permeability. J Struct Geol. 2012;45:4-20. https://doi.org/10.1016/j.jsg.2012.04.003.

Aydin A. Fractures, faults and hydrocarbon entrapment, migration and flow. Mar Pet Geol. 2000;17:797-814. https://doi. org/10.1016/S0264-8172(00)00020-9.

Bastesen E, Braathen A, Skar T. Comparison of scaling relationships of extensional fault cores in tight carbonate and porous sandstone reservoirs. Pet Geosci. 2013;19:385-98. https://doi. org/10.1144/petgeo2011-020.

Botter C, Cardozo N, Hardy S, et al. Seismic characterisation of fault damage in 3D using mechanical and seismic modelling. Mar Pet Geol. 2016;77:973-90. https://doi.org/10.1016/j.marpe tgeo.2016.08.002.

Caine SJ, Evans JP, Forster CB. Fault zone architecture and permeability structure. Geology. 1996;24:1025-8. https://doi.org/10.1130/00917613(1996)024\%3c1025:FZAAPS\%3e2.3.CO;2.

Choi JH, Edwards P, Ko K, et al. Definition and classification of fault damage zones: a review and a new methodological approach. Earth Sci Rev. 2016;152:70-87. https://doi.org/10.1016/j.earsc irev.2015.11.006.

de Joussineau G, Aydin A. The evolution of the damage zone with fault growth in sandstone and its multiscale characteristics. J Geophys Res. 2007;112:B12401. https://doi.org/10.1029/2006J B004711.

Ding WL, Fan TL, Yu BS, et al. Ordovician carbonate reservoir fracture characteristics and fracture distribution forecasting in the Tazhong area of Tarim Basin, Northwest China. J Pet Sci Eng. 2012;86-87:62-70. https://doi.org/10.1016/j.petrol.2012.03.006.

$\mathrm{Du} \mathrm{JH}$. Oil and gas exploration of Cambrian-Ordovician carbonate in the Tarim Basin. Beijing: Petroleum Industry Press; 2010 (in Chinese).

Faulkner DR, Jackson C, et al. A review of recent developments concerning the structure, mechanics and fluid flow properties of fault zones. J Struct Geol. 2010;32:1557-1575.

Faulkner DR, Mitchell TM, Jensen E, et al. Scaling of fault damage zones with displacement and the implications for fault growth processes. J Geophys Res. 2011;116:B05403. https://doi. org/10.1029/2010JB007788.

Fossen H, Hesthammer J. Possible absence of small faults in the Gullfaks Field, northern North Sea: implications for downscaling of faults in some porous sandstone. J Struct Geol. 2000;22:851-63. https://doi.org/10.1016/S0191-8141(00)00013-4.

Gao ZQ, Fan TL. Carbonate platform-margin architecture and its influence on Cambrian-Ordovician reef-shoal development, Tarim Basin, NW China. Mar Pet Geol. 2015;68:291-306. https://doi. org/10.1016/j.marpetgeo.2015.08.033.

Gudmundsson A, Guidi GD, Scudero S. Length-displacement scaling and fault growth. Tectonophysics. 2013;608:1298-309. https:// doi.org/10.1016/j.tecto.2013.06.012.

Haines TJ, Michie EAH, Neilson JE, et al. Permeability evolution across carbonate hosted normal fault zones. Mar Pet Geol. 2016;72:62-82. https://doi.org/10.1016/j.marpetgeo.2016.01.008.

Hale D. Methods to compute fault images, extract fault surfaces, and estimate fault throws from 3D seismic images. Geophysics. 2013;78:O33-43. https://doi.org/10.1190/geo2012-0331.1.

Iacopini D, Butler RWH, Purves S, et al. Exploring the seismic expression of fault zones in 3D seismic volumes. J Struct Geol. 2016;89:54-73. https://doi.org/10.1016/j.jsg.2016.05.005.

Jia CZ. Tectonic characteristics and petroleum, Tarim Basin, China. Beijing: Geological Publishing House; 1997. p. 29-261 (in Chinese).

Kim YS, Peacock DCP, Sanderson DJ. Fault damage zones. J Struct Geol. 2004;26:503-17. https://doi.org/10.1016/j.jsg.2003.08.002.

Knott SD. Fault zone thickness versus displacement in the Permo-Triassic sandstones of NW England. J Geol Soc Lond. 1994;151:1725. https://doi.org/10.1144/gsjgs.151.1.0017.
Koch M. Bootstrap inversion for vertical and lateral variations of the $\mathrm{S}$ wave structure and the op/os-ratio from shallow earthquakes in the Rhine graben seismic zone, Germany. Tectonophysics. 1992;210:91-115. https://doi.org/10.1016/00401951(92)90130-X.

Kolyukhin D, Torabi A. Statistical analysis of the relationships between fault attributes. J Geophys Res. 2012;117:B05406. https://doi. org/10.1029/2011JB008880.

Lan XD, Lü XX, Zhu YM, et al. The geometry and origin of strike-slip faults cutting the Tazhong low rise megaanticline (central uplift, Tarim Basin, China) and their control on hydrocarbon distribution in carbonate reservoirs. J Nat Gas Sci Eng. 2015;22:633-45. https ://doi.org/10.1016/j.jngse.2014.12.030.

Laubach SE, Eichhubl P, Hargrove P, et al. Fault core and damage zone fracture attributes vary along strike owing to interaction of fracture growth, quartz accumulation, and differing sandstone composition. J Struct Geol. 2014;68:207-26. https://doi.org/10.1016/j. jsg.2014.08.007.

Li QM, Wu GH, Pang XQ, et al. Hydrocarbon accumulation conditions of Ordovician carbonate in Tarim Basin. Acta Geol Sin. 2010;84:1180 94. https://doi.org/10.1111/j.1755-6724.2010.00289.x.

Li CX, Wang XF, Li BL, et al. Paleozoic fault systems of the Tazhong uplift, Tarim Basin. Mar Pet Geol. 2013;39:48-58. https://doi. org/10.1016/j.marpetgeo.2012.09.010.

Liu LF, Sun SZ, Yang HJ, et al. Seismic attributes and integrated prediction of fractured and caved carbonate reservoirs in the Tarim Basin, China. Pet Sci. 2011;8:455-61. https://doi.org/10.1007/ s12182-011-0163-8.

Lü XX, Yang N, Zhou XY, et al. Influence of Ordovician carbonate reservoir beds in Tarim Basin by faulting. Sci China Ser D. 2008;51:53-60. https://doi.org/10.1007/s11430-008-6016-7.

Mitchell TM, Faulkner DR. The nature and origin of off-fault damage surrounding strike-slip fault zones with a wide range of displacements: a field study from the Atacama fault system, northern Chile. J Struct Geol. 2009;31:802-16. https://doi.org/10.1016/j. jsg.2009.05.002.

Neng Y, Yang HJ, Deng XL. Structural patterns of fault damage zones in carbonate rocks and their influences on petroleum accumulation in Tazhong Paleo-uplift, Tarim Basin, NW China. Pet Geol Exp. 2018;45:43-54. https://doi.org/10.1016/S1876-3804(18)30004-1.

Pang XQ, Tian J, Pang H, et al. Main progress and problems in research on Ordovician hydrocarbon accumulation in the Tarim Basin. Pet Sci. 2010;7:147-63. https://doi.org/10.1007/s12182-010-0022-z.

Peacock DCP. Propagation, interaction and linkage in normal fault systems. Earth Sci Rev. 2002;58:121-42. https://doi.org/10.1016/ S0012-8252(01)00085-X.

Pei YW, Paton DA, Knipe RJ, et al. A review of fault sealing behaviour and its evaluation in siliciclastic rocks. Earth Sci Rev. 2015;150:121-38. https://doi.org/10.1016/j.earscirev.2015.07.011.

Pickering G, Peacock DCP, Sanderson DJ, et al. Modelling tip zones to predict the throw and length characteristics of faults. AAPG Bull. 1997;81:82-99. https://doi.org/10.1306/522B4299-1727-11D78645000102C1865D.

Shipton ZK, Cowie PA. Damage zone and slip-surface evolution over $\mu \mathrm{m}$ to $\mathrm{km}$ scales in high porosity Navajo Sandstone, Utah. J Struct Geol. 2001;23:1825-44. https://doi.org/10.1016/S0191 -8141(01)00035-9.

Shipton ZK, Cowie PA. A conceptual model for the origin of fault damage zone structures in high-porosity sandstone. J Struct Geol. 2003;25:333-44. https://doi.org/10.1016/S0191-8141(02)00037-8.

Torabi A, Berg SS. Scaling of fault attributes: a review. Mar Pet Geol. 2011;28:1444-60. https://doi.org/10.1016/j.marpe tgeo.2011.04.003.

Torabi A, Alaei B, Kolyukhin D. Analysis of fault scaling relations using fault seismic attributes. Geophys Prospect. 2017;65:581-95. https://doi.org/10.1111/1365-2478.12440. 
Wan XG, Wu GH, Zhang YT, et al. The seismic technique description of carbonate fault damage zone in the Tarim Basin. Oil Gas Geol. 2016;37:786-91 (in Chinese with English abstract).

Wu GH, Yang HJ, Qu TL, et al. Fault system characteristics and their controlling roles on marine carbonate hydrocarbon in the central uplift, Tarim Basin. Acta Pet Sin. 2012;28:793-805 (in Chinese with English abstract).

Wu GH, Yang HJ, He S, et al. Effects of structural segmentation and faulting on carbonate reservoir properties: a case study from the central uplift of the Tarim Basin, China. Mar
Pet Geol. 2016;71:183-97. https://doi.org/10.1016/j.marpe tgeo.2015.12.008.

Wu GH, Gao LH, Zhang YT, et al. Fracture attributes in reservoirscale carbonate fault damage zones and implications for damage zone width and growth in the deep subsurface. J Struct Geol. 2019;118:181-93. https://doi.org/10.1016/j.jsg.2018.10.008.

Zhu GY, Zhang BS, Yang HJ, et al. Origin of deep strata gas of Tazhong in Tarim Basin. Org Geochem. 2014;74:85-97. https:// doi.org/10.1016/j.orggeochem.2014.03.003. 